AGH DRILLING, OIL, GAS • Vol. $29 \cdot$ No. $4 \cdot 2012$

http://dx.doi.org/10.7494/drill.2012.29.4.447

\title{
Monika Cepil*
}

\section{THE PROBLEM OF ENGINEERING MATERIALS SELECTION IN RELATIONS TO THE EXPECTED PROPERTIES}

\section{INTRODUCTION}

Nowadays, in the selection of construction materials the most important thing is the unit price, though more expensive materials are very often replaced by cheap plastic, as long as their use provides the durability and safety of the constructions.

Even after using a lot of treatments to improve their mechanical, physical, in-use and technological properties, engineering materials sometimes do not meet the expected requirements. Therefore, today's products consist of many components made of different materials conforming to specific functions.

The subject of the presentation is to analyse the characteristics of engineering materials and the possibility of their modifications depending on the expected parameters. The presentation also focuses on the selection of materials regarding their strength calculations, working conditions (including the impact of the environment on the part of the design), application of the optimal methods of manufacturing etc.

The impact on the exploitation of the environment - also called an ecological burden of the environment is essential as well.

In modern designing (selecting construction materials) the substantial aspect is to analyse comprehensively a number of materials (metals, plastics, composition materials etc.) simultaneously, due to facilitate the lowest costs of the project in relation to the production and utilization aspects.

The design and then realisation of the construction should meet the operating, technological and economic requirements. The operating aspect encompasses the accommodation of the construction to fulfill certain tasks. Mechanical properties and toughness, wear resistance and resistance to corrosion should be taken into consideration, too. Designers

* AGH University of Science and Technology, Faculty of Drilling, Oil and Gas, Krakow, Poland 
should also be equal to choose materials which are easy to assembly and disassembly; any defects should be easy to fix in the most simplest way and cannot entrail additional complications (which comprises meeting of specifications). The economic aspects are about the profitability achieved by low costs of production involving high-efficient devices.

Mechanical properties it's not only about the toughness of the material but also should be comprised with studies on the influence of various factors to the specific property. Apart from the action of an external forces, varying of those forces with changes of temperature, way (sort, direction of force) and quantity of load should be considered as well [1].

\section{MECHANICAL PROPERTIES DETERMINATION}

Two common methods to determinate mechanical properties are:

- studies on technological properties which are the decisive factors to determinate the usefulness of materials in specific kinds of technological treatments;

- studies on the toughness of materials which lead to determinate the strains (list of loads or force moments on the static and dynamic diagram must be placed) settling on choosing of materials used to fabricate particular elements of the construction.

The first method is used to characterize the behaviour of the material's structure during the production.

For materials used to prepare casts fluidity test and plastic working test - determination of plastic properties etc. should be taken.

Fluidity (ability to fill casting dies) test, determination of cast contraction and homogeneousness of chemical composition are the factors to be focused on regarding to materials like metals. Fluidity has an influence on the macrostructure of the cast. The possibility of crevices and deformations which are the effects of the decreasing of toughness depending on strains caused by contraction can be discussed. The homogeneousness of chemical composition has also the influence on the toughness of the material.

During the selection of engineering materials the second presented method of characterization is the most meaningful; the mentioned method is focused on the toughness of the material. In a static tensile test, tensile forces are applied to normalized sample made of tested material, forces are alongside to the axis of a tested rod.

Then, tensile strains are observed in any direction perpendicular to the direction of force acting. Relative elongation of quantity of $\varepsilon$ is caused by tensile strain. Stress-strain curve for tested material is shown on Figure 1.

When elastic deformations are present in tested materials, small initial elongation caused by a large change of force can be observed. Plastic deformations, apart from elastic deformations, are observed when amount of the force exceeds certain threshold value. The strains exceeding the yield limit of tested material causing further elongation of the sample. When the maximal value $R_{m}$ is crested, the sample broke off and the amount of the strain is decreasing. Stress-strain curves for the number of selected materials are shown on Figure 2. 


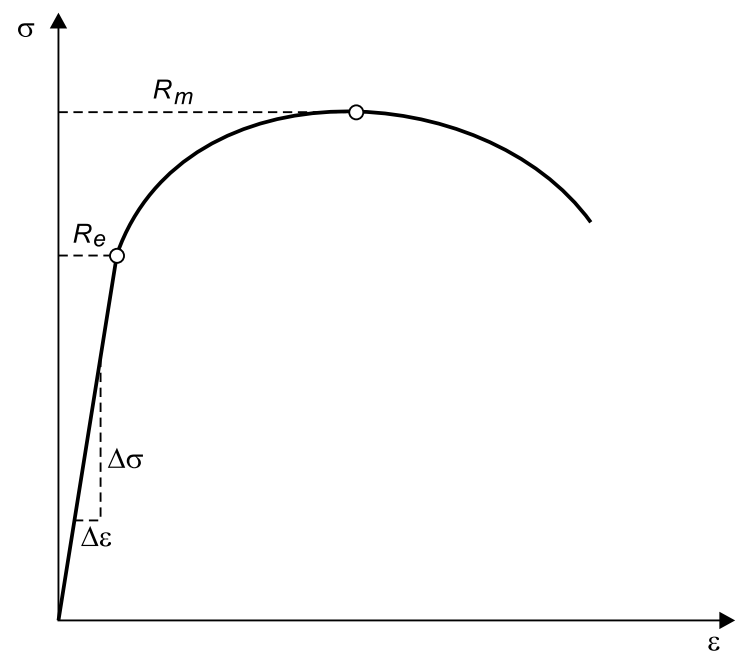

Fig. 1. Exemplary stress-strain curve [2]

a) $\sigma \uparrow \quad$ plastic materials

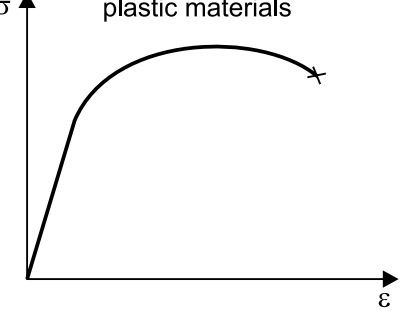

b) $\sigma \uparrow \quad$ brittle materials

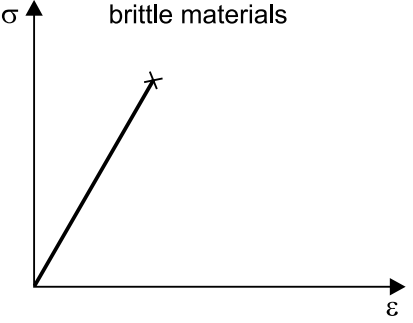

c) $\sigma \uparrow$ metals

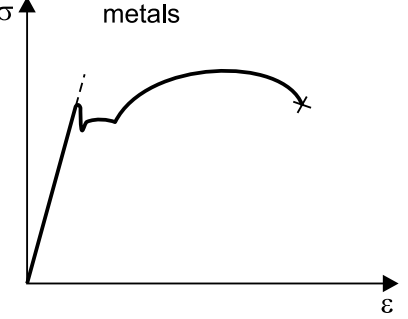

Fig. 2. Stress-strain curve for plastic: a) plastic materials; b) brittle materials; c) metals [2] 
The capacity to withstand pushing forces is determined mostly for brittle materials, like cast iron or ceramic. During the test, force is applied perpendicularly to cross-section of a cylinder-shaped sample. After cresting the certain threshold value, the sample is destroyed, like in previously described method.

By creep strength is defined the maximal strain, which causes elongation of material in a way of creep. Figure 3 shows exemplary creep curve.

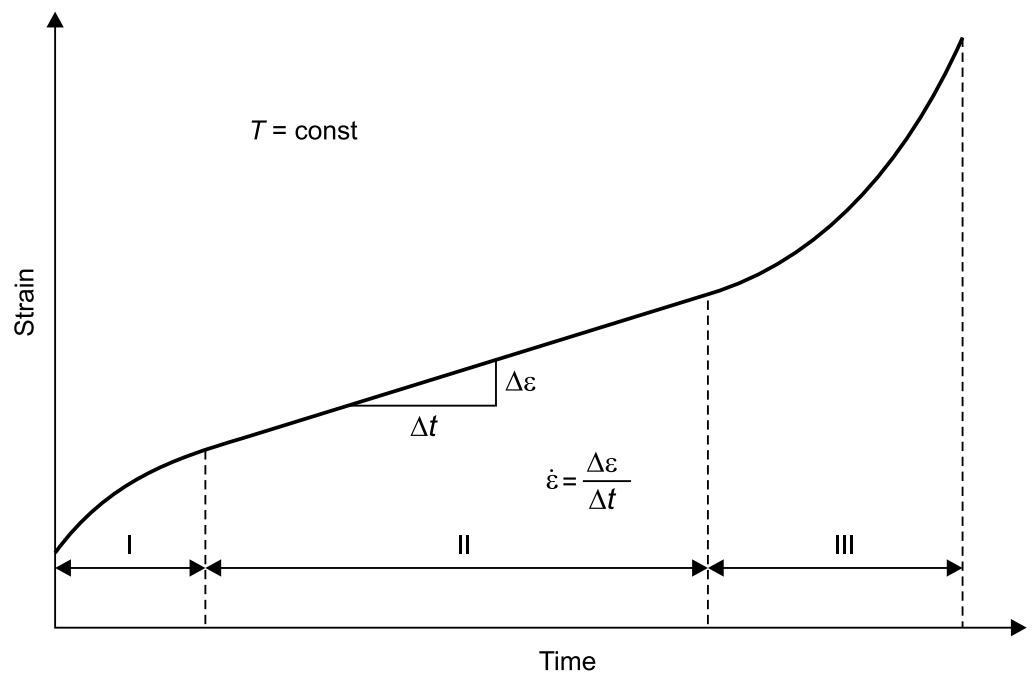

Fig. 3. Creep curve [2]

Three regions of creep at constant load and constant temperature can be distinguished from the presented curve. In the first stage large deformation in a short time period can be observed. The second stage corresponds to slow and steady permanent deformations. The last stage is related to rapid increase of elongation, finished with breaking the sample off. Influence of temperature and time on the trace of creep curves shows Figure 4.

a)

$T=$ const

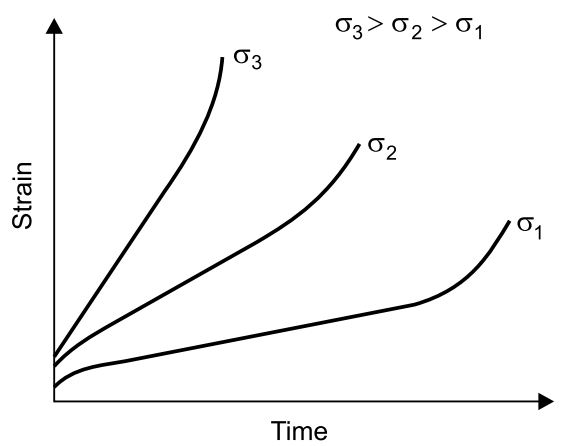

b)

$$
\sigma=\text { const }
$$

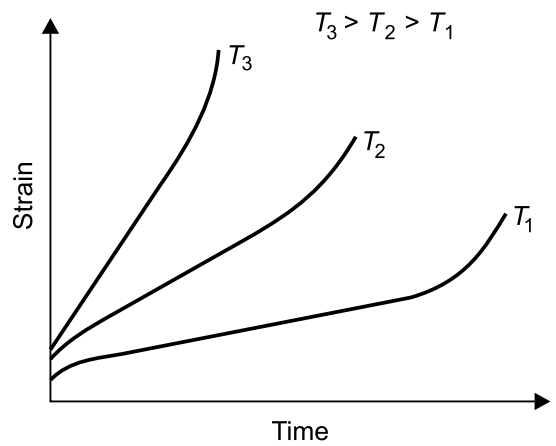

Fig. 4. Influence of temperature and time on the trace of creep curves [2] 
Chemical properties and resistance to the environmental factors appealing to chosen material are also important during the selection of materials. Corrosion is caused by the irresistanceof metal to the circumambience which contains agents like air, water or acids. Galvanic corrosion is the most frequent phenomenon in the moist surroundings

\section{CONCLUSIONS}

Proper selection of materials with fulfilment of the defined assumptions can bring tangible business advantages. The most important factors are:

- increasing the accuracy of toughness calculations, which is connected with decreasing of factors of safety;

- understanding the details of operation of the machines and environmental factors affecting the devices;

- discovering new ways of optimal productions.

The broadly taken safety and preventing failures of devices or destruction of materials are still the most significant factors during the whole process.

\section{REFERENCES}

[1] Ciszewski A., Radomski T.: Materiaty konstrukcyjne w budowie maszyn. PWN, Warszawa 1989.

[2] Kuźnicka B.: Materiałoznawstwo: materiały pomocnicze dla studentów MWSLiT we Wrocławiu. Oficyna Wydawnicza „Nasz Dom i Ogród”, Wrocław 2003.

[3] Okoniewski S.: Materiały konstrukcyjne. Cz. 1. Państwowe Wydawnictwa Szkolnictwa Zawodowego, Warszawa 1973.

[4] Budownictwo ogólne. Tom 1: Materiały i wyroby budowlane. Arkady, Warszawa 2005. 